\title{
Long COVID: where do we start with the case definitions?
}

\author{
Nisreen A Alwan ${ }^{123}$, Luke Johnson ${ }^{1}$
}

\author{
${ }^{1}$ School of Primary Care, Population Sciences and Medical Education, Faculty of Medicine, University \\ of Southampton, Southampton, UK \\ ${ }^{2}$ NIHR Southampton Biomedical Research Centre, University of Southampton and University Hospital \\ Southampton NHS Foundation Trust, Southampton, UK \\ ${ }^{3}$ NIHR Applied Research Collaboration Wessex, Southampton, UK
}

\begin{abstract}
Long COVID is the condition whereby individuals do not recover for several weeks or months following the onset of COVID19 symptoms. The range of reported symptoms is very wide. There are no agreed case definitions for Long COVID leading to variation in clinical diagnosis, especially if individuals were not tested when initially infected. We propose criteria to establish a retrospective diagnosis of 'Past Acute COVID'. In the presence of continuing symptoms, this provides a standardised way to case-define Long COVID. We reviewed multiple official case definitions of suspected, probable, and confirmed COVID19 to reach the proposed criteria. For people presenting with continued ill health or disability more than 4 weeks following an initial acute illness, meeting one or more of the following criteria would classify them as having had Past Acute COVID:

1) Positive COVID19 PCR or antigen test

2) Positive COVID19 antibody test

3) Loss of sense of smell or taste in the absence of any other identified cause

4) Common clinical symptoms according to the WHO: either the combination of acute onset fever and cough; or at least THREE of any of the following symptoms and signs: fever, cough, general weakness/fatigue, headache, myalgia, sore throat, coryza, dyspnoea, anorexia/nausea/vomiting, diarrhoea, altered mental status) AND high prevalence of COVID19 at time and location of onset

5) At least ONE common clinical symptom (as above) AND contact of a confirmed case of COVID19 around the time of onset
\end{abstract}

Survival in the short-term does not equal recovery from COVID19. Until we know more about the nature of the long-term health effects of COVID19, the proposed criteria to establish Past Acute COVID in those who have not recovered offer a pragmatic and inclusive way to classify and quantify Long COVID. 


\section{Prevalence of Long Covid}

Measuring morbidity from COVID19 is an immediate priority in this pandemic. There is emerging evidence of long-term health impairment and organ damage across the spectrum of the clinical presentation of COVID19 infection [1-3]. Long COVID is the condition whereby affected individuals do not recover for several weeks or months following the onset of symptoms suggestive of COVID19 infection, whether they were tested or not [4]. In lab-confirmed COVID19 patients who were hospitalised, persistent ill health seems to be very common, with ongoing symptoms including breathlessness, cough, fatigue and mental health problems [5-7]. In those with so-called 'mild' COVID19 who were not hospitalised at all, or not initially hospitalised, the prevalence of Long COVID is still uncertain.

There are two main issues we are faced with when measuring the prevalence of Long COVID, particularly in non-hospitalised, non-lab-confirmed people. The first one is the denominator. Everyone infected with COVID19, or at least all those initially symptomatic, should be counted in the denominator. The second issue is the numerator. Standardisation of case definitions, at least for the sake of comparison across different settings and population groups, needs to be in place.

Evidence from relatively small studies suggests approximately one-third of non-hospitalised COVID19 patients not going back to usual health after 2-6 weeks from onset of illness or positive PCR test date [8-10]. Out of those, a proportion still present later in their illness to the emergency department, some of whom require hospitalisation [9]. Around 11-24\% of COVID19 cases still have persisting symptoms three months after onset of illness [11,12]. One study reported persistence of at least one symptom after a mean of 125 days from onset in $53 \%$ of those included [13]. Estimates vary because of different study designs, recruitment settings, questions asked, and number of symptoms assessed as 'recovered' or not. One way to measure the prevalence of Long COVID is to define it by what it is not: full recovery from COVID19 infection [14]. However, surveillance systems are not assessing recovery in any standardised or consistent way [15].

Recent estimates from the UK's Office of National Statistics (ONS), derived using a Kaplan-Meier approach based on a sample of 8,193 respondents, point to a Long COVID prevalence of $21 \%$ at 5 weeks, and $10 \%$ at 12 weeks from onset [16]. However, this was based on a list of 12 symptoms as asked by the ONS COVID19 infection survey [17], with some of the common symptoms of Long COVID such as chest heaviness, palpitations and neurological manifestations missing from that list.

\section{Case definitions}

Standard clinical case definitions would provide healthcare professionals with systematic and inclusive criteria to aid diagnosis in patients with ongoing symptoms. Patients presenting with Long COVID often face the dilemma that their original acute infection was not formally diagnosed because of issues with lab test availability, accessibility, feasibility, and accuracy. c, many of these patients would not have initially required or sought medical care. This potentially results in later health concerns not being adequately addressed because of the lack of diagnosis in the acute phase.

Discrimination in investigations and care pathways based on test results also risks exacerbating health inequalities. There are still numerous disincentives to seeking testing early in the illness. These include stigma, difficulty in accessing tests, and barriers against self and household isolation including loss of income, care networks and essential social support. These disincentives are much stronger in disadvantaged populations. The available tests are also not accurate enough, with a relatively high false negative rate [18]. Many people present later to healthcare with Long COVID to seek medical management, access to sick pay and benefits. Evidence of waning antibody positivity 
also means these tests cannot be used in isolation to determine if persistent symptoms are related to Long COVID [19].

The recent National Institute for Health and Care Excellence (NICE) rapid guideline on managing the long-term effects of COVID19 stresses the importance of not excluding people from clinical assessment in the absence of a positive SARSCoV2 test. It uses the terminology of 'Ongoing Symptomatic COVID-19' for "signs and symptoms of COVID19 from 4 to 12 weeks", and 'PostCOVID19 Syndrome" for "signs and symptoms that develop during or after an infection consistent with COVID-19, continue for more than 12 weeks and are not explained by an alternative diagnosis" [20]. These definitions are vague and do not classify the initial or subsequent patterns of symptoms in a way that would help lessen the variation in diagnosis and referral among different clinicians.

Part of the problem is that there is still no formal guidance on criteria to diagnose probable initial COVID19 infection for those presenting with Long COVID symptoms later in their illness. One way to standardise and facilitate diagnosis and make it more inclusive is to use a retrospective case definition for the initial probable infection. Therefore, for someone presenting to healthcare with prolonged symptoms, establishing the initial acute episode using set criteria can provide the diagnosis of Long COVID. This can be used not only clinically, but also to inform surveillance estimates of COVID19 persistent symptoms and pathology.

Currently, case definitions and diagnostic criteria for 'possible', 'suspected' and 'probable' acute COVID19 vary between countries and international public health agencies. Table 1 gives examples of this variation. We considered 'possible' and 'suspected' COVID19 definitions as one category, as this appeared to be a variance in nomenclature between countries instead of reflecting a different likelihood of COVID19 infection. Clinical criteria alone define a possible/suspected case in most national/international case definitions. WHO also considers "new onset anosmia or ageusia in the absence of any other identified cause" as sufficient for probable COVID19 [21].

For the majority of reviewed definitions, clinical criteria plus either epidemiological criteria or radiological criteria upgrade cases to probable COVID19. Criteria for a confirmed case are invariably lab-based, mostly by nucleic acid amplification tests (NAAT), most commonly Polymerase Chain Reaction (PCR). There is huge variability in how the result of antibody tests are interpreted in case definitions. CDC guidance for example considers a positive antibody result as only possible COVID19 [22], France considers it as confirmed [23], and Australia and New Zealand interpret results based on how elevated antibody levels are $[24,25]$.

Epidemiological criteria are understandably heterogenous due to variation in local prevalence of COVID19. Australia, New Zealand, France, and Norway focus on whether an individual has recently travelled internationally, or been in contact with a probable or confirmed case [23-26]. ECDC, Canada and Ireland additionally include places or gatherings known to be outbreaks [27-29]. WHO and Canada pragmatically include communities or regions of known high transmission as a sufficient risk factor in their epidemiological criteria [21,27]. Several countries already have case definition criteria which would potentially enable retrospective diagnosis, whether by clinical and epidemiological history, or through an antibody test (USA, Australia, New Zealand, Canada, France, Norway) [22-27]. England only had criteria to help determine when to order a NAAT test for COVID19 and no information to help facilitate retrospective diagnosis [30]. We used the similarities between the different guidelines to suggest retrospective case definitions for acute COVID19 infection. 


\section{Past Acute COVID}

We propose the following as criteria for retrospective diagnosis of COVID19, which we refer to as "Past Acute COVID". Note, however, this term does not insinuate that symptoms have necessarily resolved - as stated earlier, the primary purpose is to help facilitate Long COVID diagnosis in people with ongoing symptoms. Any one of the following criteria would be sufficient for diagnosis:

1) Positive COVID19 PCR or antigen test

2) Positive COVID19 antibody test

3) Loss of sense of smell or taste in the absence of any other identified cause

4) Common clinical symptoms AND high prevalence of COVID19 at time and location of onset

5) At least one common clinical symptom AND contact of a confirmed case of COVID19 around the time of onset

COVID19 antibody test has variable sensitivity but high specificity, and antibody titres are likely to reduce the longer after infection an individual is tested [19,31]. Therefore, a positive result would be sufficient to diagnose past acute COVID, but a negative result insufficient to exclude it.

Loss of sense of smell and taste has been shown to be the symptom which best predicts COVID19 infection and has been used as a definition by the WHO for a probable case [21,32]. We therefore argue it is sufficient to be used alone here for diagnosing past acute COVID too.

For the clinical symptoms definition in criteria 4 and 5, we propose the WHO clinical criteria of either the presence of both acute onset fever and cough; or the combination of any three or more of the following symptoms and signs: fever, cough, general weakness/fatigue, headache, myalgia, sore throat, coryza, dyspnoea, anorexia/nausea/vomiting, diarrhoea, altered mental status [21].

Finally, the definition of "high prevalence of COVID19" must be country- and time-specific. Prevalence can be underestimated depending on the availability of testing within a country during a given time-period. Further, unmeasured regional variations in transmission can result in under- or over-estimations in local prevalence. Even mortality rate has its limitations as a measure of prevalence [33]. One source of regional prevalence information could be national COVID19 prevalence surveys $[17,34]$.

Standardising retrospective case definitions for COVID19 has two primary purposes. Firstly, it will enable clinicians to retrospectively diagnose COVID19, enabling them to order relevant investigations and provide patients with Long COVID access to treatment and rehabilitation. By providing a solid diagnosis, clinicians will be able to further benefit patients by making sense of their symptoms. Secondly, it will enable surveillance systems to better assess the prevalence of COVID19 morbidity, thereby informing the planning of needed services and public health interventions.

Once there is stronger evidence on the natural history and clinical spectrum of Long COVID symptoms, additional criteria relating to the presence of typical Long COVID symptoms could be added later to be used alongside the retrospective case definition. Until then, we believe the five criteria presented above provide a sufficient and inclusive guide for the diagnosis of Past Acute COVID, which then forms the basis of counting and managing Long COVID, including cases that have not been initially lab-confirmed.

\section{Long COVID known unknowns}

Past Acute COVID criteria start to address one of the main pressing questions around Long COVID case definitions. In addition to ascertaining the prevalence of Long COVID in different population 
groups, which is an immediate priority (counting Long COVID), there are many other 'known unknowns' in this area. These include the following:

1. Who is more likely to get Long COVID? What are the risk factors?

2. Who is more likely to recover from it?

3. How can it be treated?

4. Why do people get it? What are the underlying mechanisms?

5. Is there genetic susceptibility to Long COVID?

6. Is it one medical condition or several distinct ones?

7. What is the prognosis?

8. What are the distinct patterns of symptoms? Can they predict progression, prognosis, and response to treatment?

9. What can be done in the acute phase of COVID19 infection to prevent progression to Long COVID?

10. What is the burden it exerts on the economy, health, and care systems?

11. How will disadvantaged and marginalised groups affected by Long COVID be protected in term of care, prevention, and employment rights?

12. Can Long COVID patients get re-infected? If this is possible, does it mean clinical deterioration?

13. Should Long COVID patients be 'shielding'?

14. Should Long COVID patients receive the COVID19 vaccine? Should they be on the priority list?

15. What does Long COVID look like in children?

COVID19 infection can no longer been described in black and white. There is a huge grey area of those who survived COVID19 in the short-term but have not recovered. One of the main challenges of the next phase of this global pandemic is to quantify Long COVID, prepare the different systems across society for its enormity, help those affected by it in an equitable manner, and prevent more from progressing to it. This is the task ahead of us. It is extremely complex and daunting but unavoidable. 
Table 1: Official case definition criteria for COVID19 by country/organisation

\begin{tabular}{|c|c|c|c|}
\hline Organisation/Country & $\begin{array}{l}\text { Possible/suspected } \\
\text { case }\end{array}$ & Probable case & Confirmed case \\
\hline WHO [21] & $\begin{array}{l}\text { Clinical criteria) + } \\
\text { epidemiological } \\
\text { criteria } \\
\text { (Clinical criteria = } \\
\text { acute onset fever and } \\
\text { cough; or any three or } \\
\text { more of fever, cough, } \\
\text { general } \\
\text { weakness/fatigue, } \\
\text { headache, myalgia, } \\
\text { sore throat, coryza, } \\
\text { dyspnoea, } \\
\text { anorexia/nausea/vomi } \\
\text { ting, diarrhoea, } \\
\text { altered mental state) }\end{array}$ & $\begin{array}{l}\text { A) Clinical criteria + } \\
\text { contact of a } \\
\text { probable/confirmed } \\
\text { case, or } \\
\text { epidemiologically } \\
\text { linked to a cluster with } \\
\text { at least one confirmed } \\
\text { case } \\
\text { B) Chest imaging } \\
\text { suspicious for } \\
\text { COVID19 } \\
\text { C) New onset anosmia } \\
\text { or ageusia in the } \\
\text { absence of any other } \\
\text { identified cause } \\
\text { D) Death, not } \\
\text { otherwise explained, } \\
\text { in adult with } \\
\text { respiratory distress } \\
\text { preceding death + } \\
\text { contact of a } \\
\text { probable/confirmed } \\
\text { case, or } \\
\text { epidemiologically } \\
\text { linked to a cluster with } \\
\text { at least one confirmed } \\
\text { case }\end{array}$ & $\begin{array}{l}\text { Laboratory } \\
\text { confirmation of } \\
\text { COVID19 }\end{array}$ \\
\hline$E C D C[35]$ & Clinical criteria & $\begin{array}{l}\text { A) Clinical criteria + } \\
\text { epidemiological } \\
\text { criteria } \\
\text { B) Radiological } \\
\text { evidence of COVID19 }\end{array}$ & $\begin{array}{l}\text { COVID19 NAAT test } \\
+ \text { ve }\end{array}$ \\
\hline $\begin{array}{l}\text { UK - Public Health } \\
\text { England [30] }\end{array}$ & A) Clinical criteria & & $\begin{array}{l}\text { COVID19 NAAT test } \\
+ \text { +ve }\end{array}$ \\
\hline USA/CDC [22] & $\begin{array}{l}\text { A) COVID19 Ab test } \\
\text { positive } \\
\text { B) COVID19 antigen } \\
\text { positive in autopsy } \\
\text { specimen }\end{array}$ & $\begin{array}{l}\text { A) Clinical criteria+ } \\
\text { epidemiological } \\
\text { linkage } \\
\text { B) COVID19 Antigen } \\
\text { positive in respiratory } \\
\text { specimen } \\
\text { C) COVID19 on death } \\
\text { certificate as cause of } \\
\text { death or contributing } \\
\text { to cause of death }\end{array}$ & COVID19 NAAT +ve \\
\hline Australia [25] & $\begin{array}{l}\text { Clinical criteria + } \\
\text { epidemiological } \\
\text { criteria }\end{array}$ & $\begin{array}{l}\text { A) COVID19 Ab test } \\
\text { positive }+ \text { has had } \\
\text { compatible clinical }\end{array}$ & $\begin{array}{l}\text { A) COVID19 NAAT +ve } \\
\text { B) Virus isolation in } \\
\text { cell culture, with PCR }\end{array}$ \\
\hline
\end{tabular}




\begin{tabular}{|c|c|c|c|}
\hline & & $\begin{array}{l}\text { symptoms + } \\
\text { epidemiological } \\
\text { linkage }\end{array}$ & $\begin{array}{l}\text { confirmation using a } \\
\text { validated method } \\
\text { C) Significant rise in } \\
\text { COVID19 Ab test (4- } \\
\text { fold rise in titre) }\end{array}$ \\
\hline New Zealand [24] & & $\begin{array}{l}\text { A) Clinical criteria + } \\
\text { epidemiological } \\
\text { criteria but testing } \\
\text { unavailable } \\
\text { B) Clinical criteria + } \\
\text { epidemiological } \\
\text { criteria + negative } \\
\text { NAAT >7 days after } \\
\text { symptom onset }\end{array}$ & $\begin{array}{l}\text { A) COVID19 NAAT +ve } \\
\text { B) Significant rise on } \\
\text { COVID19 Ab test } \\
\text { result }\end{array}$ \\
\hline Canada [27] & $\begin{array}{l}\text { Clinical criteria + } \\
\text { epidemiological } \\
\text { criteria }\end{array}$ & $\begin{array}{l}\text { A) Clinical criteria + } \\
\text { epidemiological } \\
\text { criteria + inconclusive } \\
\text { laboratory test result } \\
\text { B) Clinical criteria + } \\
\text { known COVID19 } \\
\text { exposure (confirmed } \\
\text { case/confirmed } \\
\text { outbreak venue) }\end{array}$ & COVID19 NAAT+ve \\
\hline Ireland [29] & Clinical criteria & $\begin{array}{l}\text { A) Clinical criteria + } \\
\text { epidemiological } \\
\text { criteria } \\
\text { B) Radiological } \\
\text { evidence of COVID19 }\end{array}$ & COVID19 NAAT+ve \\
\hline France [23] & Clinical criteria & $\begin{array}{l}\text { Clinical criteria + } \\
\text { radiological evidence } \\
\text { of COVID19 }\end{array}$ & $\begin{array}{l}\text { A) COVID19 NAAT+ve } \\
\text { B) COVID19 Ab test } \\
+ \text { +ve }\end{array}$ \\
\hline Norway [26] & Clinical criteria & $\begin{array}{l}\text { Clinical criteria + } \\
\text { epidemiological } \\
\text { criteria }\end{array}$ & COVID19 NAAT+ve \\
\hline
\end{tabular}

\section{Competing interest statement:}

NAA had/has symptoms of Long COVID. In October 2020, NAA provided expert feedback in relation to one scoping meeting for the NICE/SIGN/RCGP Long COVID Rapid Guideline.

\section{Author contributions:}

NAA conceived the article's concept. LJ collated the data in table 1. Both authors drafted and finalised the manuscript.

\section{Patient and Public Involvement statement:}

Public contributors were involved in the conceptualisation of the Past Acute COVID criteria.

\section{Dissemination to study participants:}

Not applicable 


\section{References:}

1 Puntmann VO, Carerj ML, Wieters I, et al. Outcomes of Cardiovascular Magnetic Resonance Imaging in Patients Recently Recovered From Coronavirus Disease 2019 (COVID-19). JAMA Cardiology Published Online First: 27 July 2020. doi:10.1001/jamacardio.2020.3557

2 del Rio C, Collins LF, Malani P. Long-term Health Consequences of COVID-19. JAMA Published Online First: 5 October 2020. doi:10.1001/jama.2020.19719

3 Dennis A, Wamil M, Kapur S, et al. Multi-organ impairment in low-risk individuals with long COVID. medRxiv 2020;:2020.10.14.20212555. doi:10.1101/2020.10.14.20212555

4 Nabavi N. Long covid: How to define it and how to manage it. BMJ 2020;370. doi:10.1136/bmj.m3489

5 Mandal S, Barnett J, Brill SE, et al. 'Long-COVID': a cross-sectional study of persisting symptoms, biomarker and imaging abnormalities following hospitalisation for COVID-19. Thorax Published Online First: 10 November 2020. doi:10.1136/thoraxjnl-2020-215818

$6 \mathrm{D}^{\prime}$ Cruz RF, Waller MD, Perrin F, et al. Chest radiography is a poor predictor of respiratory symptoms and functional impairment in survivors of severe COVID-19 pneumonia. ERJ Open Research Published Online First: 1 January 2020. doi:10.1183/23120541.00655-2020

7 Chopra V, Flanders SA, O'Malley M, et al. Sixty-Day Outcomes Among Patients Hospitalized With COVID-19. Ann Intern Med Published Online First: 11 November 2020. doi:10.7326/M20-5661

8 Tenforde MW. Symptom Duration and Risk Factors for Delayed Return to Usual Health Among Outpatients with COVID-19 in a Multistate Health Care Systems Network - United States, March-June 2020. MMWR Morb Mortal Wkly Rep 2020;69. doi:10.15585/mmwr.mm6930e1

9 Blair PW, Brown DM, Jang M, et al. The clinical course of COVID-19 in the outpatient setting: a prospective cohort study. medRxiv 2020;:2020.09.01.20184937. doi:10.1101/2020.09.01.20184937

10 Nehme M, Braillard O, Alcoba G, et al. COVID-19 Symptoms: Longitudinal Evolution and Persistence in Outpatient Settings. Ann Intern Med Published Online First: 8 December 2020. doi:10.7326/M20-5926

11 Ding $\mathrm{H}$, Yin S, Cheng $\mathrm{Y}$, et al. Neurologic manifestations of nonhospitalized patients with COVID-19 in Wuhan, China. MedComm 2020;1:253-6. doi:10.1002/mco2.13

12 Cirulli E, Barrett KMS, Riffle S, et al. Long-term COVID-19 symptoms in a large unselected population. medRxiv 2020;:2020.10.07.20208702. doi:10.1101/2020.10.07.20208702

13 Petersen MS, Kristiansen MF, Hanusson KD, et al. Long COVID in the Faroe Islands - a longitudinal study among non-hospitalized patients. Clinical Infectious Diseases Published Online First: 30 November 2020. doi:10.1093/cid/ciaa1792

14 Alwan NA. A negative COVID-19 test does not mean recovery. Nature 2020;584:170-170. doi:10.1038/d41586-020-02335-z

15 Alwan NA. Surveillance is underestimating the burden of the COVID-19 pandemic. The Lancet 2020;396:e24. doi:10.1016/S0140-6736(20)31823-7 
16 Prevalence of long COVID symptoms and COVID-19 complications - Office for National Statistics.

https://www.ons.gov.uk/peoplepopulationandcommunity/healthandsocialcare/healthandlifeexp ectancies/datasets/prevalenceoflongcovidsymptomsandcovid19complications (accessed 18 Dec 2020).

17 Coronavirus (COVID-19) Infection Survey, UK Statistical bulletins - Office for National Statistics.

https://www.ons.gov.uk/peoplepopulationandcommunity/healthandsocialcare/conditionsanddis eases/bulletins/coronaviruscovid19infectionsurveypilot/previousReleases (accessed $18 \mathrm{Dec}$ 2020).

18 Watson J, Whiting PF, Brush JE. Interpreting a covid-19 test result. BMJ 2020;369. doi:10.1136/bmj.m1808

19 Ward H, Cooke G, Atchison C, et al. Declining prevalence of antibody positivity to SARS-CoV2: a community study of 365,000 adults. medRxiv 2020;:2020.10.26.20219725.

doi:10.1101/2020.10.26.20219725

20 COVID-19 rapid guideline: managing the long-term effects of COVID-19 | Guidance | NICE. https://www.nice.org.uk/guidance/ng188 (accessed 18 Dec 2020).

21 WHO COVID-19 Case definition. https://www.who.int/publications-detail-redirect/WHO2019-nCoV-Surveillance_Case_Definition-2020.1 (accessed 2 Nov 2020).

22 Coronavirus Disease 2019 (COVID-19) | 2020 Interim Case Definition, Approved August 5, 2020. /nndss/conditions/coronavirus-disease-2019-covid-19/case-definition/2020/08/05/ (accessed 2 Nov 2020).

23 Santé publique France. Définition de cas d'infection au SARS-CoV-2 (COVID-19). 2020. https://www.santepubliquefrance.fr/content/download/228073/file/COVID19_definition_cas_20200403.pdf (accessed 11 Mar 2020).

24 Ministry of Health New Zealand. Case definition and testing guidance for COVID-19. Ministry of Health NZ. https://www.health.govt.nz/our-work/diseases-and-conditions/covid-19-novelcoronavirus/covid-19-information-health-professionals/case-definition-and-testing-guidancecovid-19 (accessed 2 Nov 2020).

25 Australia CDN, Health AGD of. Coronavirus Disease 2019 (COVID-19) CDNA National guidelines for public health units.

https://www1.health.gov.au/internet/main/publishing.nsf/Content/cdna-song-novelcoronavirus.htm (accessed 2 Nov 2020).

26 Norwegian Institute of Public Health. Definitions of COVID-19 cases and close contacts. Norwegian Institute of Public Health. https://www.fhi.no/en/op/novel-coronavirus-factsadvice/testing-and-follow-up/definitions-of-probable-and-confirmed-cases-of-coronavirus-covid19-and-con/ (accessed 2 Nov 2020).

27 Canada PHA of. Interim national case definition: Coronavirus disease (COVID-19). aem. 2020.https://www.canada.ca/en/public-health/services/diseases/2019-novel-coronavirusinfection/health-professionals/national-case-definition.html (accessed 2 Nov 2020). 
28 Case definition for coronavirus disease 2019 (COVID-19), as of 29 May 2020. European Centre for Disease Prevention and Control. https://www.ecdc.europa.eu/en/covid-

19/surveillance/case-definition (accessed 2 Nov 2020).

29 Case Definitions - Health Protection Surveillance Centre. https://www.hpsc.ie/az/respiratory/coronavirus/novelcoronavirus/casedefinitions/\#: :text=COVID\%2D19\%20interim\%2 Ocase\%20definition,-

Version\%205.9\&text=A\%20patient\%20with\%20severe\%20acute,fully\%20explains\%20the\%20clini cal\%20presentation (accessed 2 Nov 2020).

30 COVID-19: investigation and initial clinical management of possible cases. GOV.UK. https://www.gov.uk/government/publications/wuhan-novel-coronavirus-initial-investigation-ofpossible-cases/investigation-and-initial-clinical-management-of-possible-cases-of-wuhan-novelcoronavirus-wn-cov-infection (accessed 14 Aug 2020).

31 Bastos ML, Tavaziva G, Abidi SK, et al. Diagnostic accuracy of serological tests for covid-19: systematic review and meta-analysis. BMJ 2020;370. doi:10.1136/bmj.m2516

32 Menni C, Valdes AM, Freidin MB, et al. Real-time tracking of self-reported symptoms to predict potential COVID-19. Nature Medicine 2020;:1-4. doi:10.1038/s41591-020-0916-2

33 Report 34 - COVID-19 Infection Fatality Ratio Estimates from Seroprevalence. Imperial College London. http://www.imperial.ac.uk/medicine/departments/school-publichealth/infectious-disease-epidemiology/mrc-global-infectious-disease-analysis/covid-19/report34-ifr/ (accessed 2 Nov 2020).

34 Real-time Assessment of Community Transmission (REACT) Study. Imperial College London. http://www.imperial.ac.uk/medicine/research-and-impact/groups/react-study/ (accessed 18 Dec 2020).

35 Case definition for coronavirus disease 2019 (COVID-19), as of 29 May 2020. https://www.ecdc.europa.eu/en/covid-19/surveillance/case-definition (accessed 14 Aug 2020). 